\title{
FORMALIZAÇÃO DA ESTRATÉGIA EM EMPRESAS NASCENTES DE BASE TECNOLÓGICA: RECURSOS ALTERNATIVOS NA FRAGILIDADE DO NOVO.
}

\section{RESUMO}

O presente artigo busca investigar as potencialidades da utilização de métodos alternativos no suporte à definição, formalização, execução e acompanhamento das estratégias de uma empresa nascente de base tecnológica. Em um contexto de fragilidade do novo, com limitações de recursos e de infraestrutura, o processo de ganho de escala de startups pode ser dificultado por pontos como inexperiência gerencial, discrepância competitiva e fragilidade frente a instabilidades do mercado. Sob essa conjuntura, a busca por suporte para a estratégia do negócio em sua escalabilidade se mostra vital, porém, ainda tido como distante devido aos custos envolvidos à aquisição deste tipo de apoio se mostrarem impeditivos para empresas nascentes. O estudo propôs a realização de uma intervenção baseada na absorção de conhecimentos por meio de um Massive Online Open Course, mecanismo alternativo para superar os desafios acima apresentados. Deste modo, a investigação, cujo método se estruturou na pesquisa-ação, se atentou na identificação de resultados gerados por esse modelo alternativo de suporte. A revisão teórica perpassou pelos tópicos: (i) o papel da estratégia em empresas de base tecnológica, (ii) empreendedorismo tecnológico e a fragilidade do novo e (iii) plataformas abertas de educação como elemento de capacitação em estratégia. Os resultados, além de levantamentos colhidos em um grupo focal para identificação dos principais ganhos, se mostraram em relativo médio prazo, com a empresa demonstrando resultados gerenciais relevantes.

Palavras-Chave: Estratégia; Startups; Massive Online Open Course.

\section{STRATEGY FORMALIZATION IN EMERGING COMPANIES OF TECHNOLOGICAL BASIS: ALTERNATIVE RESOURCES IN THE LIABILITY OF NEWNESS.}

\begin{abstract}
ABSRTRACT
This paper aims to investigate the potential use of alternative methods in supporting the definition, formulation, implementation and follow-up of the strategies in an emerging technology-based company. In a liability of newness context, with limited resources and infrastructure, the process of startups scale gain may be hampered by subjects as managerial inexperience, competitive discrepancy and fragility against the market instabilities. Under this scenario, the search for support for the business strategy in its scalability proves to be vital; however, still considered distant due to the costs involved in the acquisition of such support, it proves to be prohibitive for emerging companies. The study has proposed an intervention based on the absorption of knowledge through a Massive Online Open Course, an alternative mechanism to overcome the challenges listed above. In this manner, the research, whose method is structured in action researches, was based on the identification of the results generated by this support alternative model. The theoretical review pervaded by the topics: (i) the role of strategy in technology-based companies, (ii) technological entrepreneurship and the liability of newness and (iii) open education platforms as a training element in strategy. The results, as well as the surveys collected in a focus group in order to identify the main gains, have appeared in a relative medium term and the company has demonstrated relevant managerial results.
\end{abstract}

Keywords: Strategy; StartupS; Massive Online Open Course. 
ESTRATEGIA FORMALIZACIÓN EN LOS NEGOCIOS DE BASE TECNOLÓGICA SPRINGS RECURSOS EN ALTERNATIVA NUEVA DEBILIDAD.

\section{RESUMEN}

En este trabajo se investiga el posible uso de métodos alternativos en el apoyo a la definición, formulación, aplicación y seguimiento de las estrategias de una empresa incipiente de base tecnológica. En un nuevo entorno frágil, con recursos limitados y la infraestructura, el proceso de nuevas empresas de escala de ganancia puede verse obstaculizado por puntos como la falta de experiencia de gestión, discrepancia competitiva y fragilidad contra la inestabilidad del mercado. Bajo este escenario, la búsqueda de apoyo a la estrategia de negocio en su escalabilidad resulta vital, sin embargo, sigue siendo visto como distante debido a los costos involucrados en la adquisición de este tipo de apoyo resultar prohibitivo para empresas de nueva creación. El estudio ha propuesto llevar a cabo una intervención basada en la absorción del conocimiento por un mecanismo alternativo Curso en línea abierto masivo para superar los retos enumerados anteriormente. Por lo tanto, la investigación, el método que se estructura en la investigación-acción, si se veía en los resultados de identificación generados por este apoyo modelo alternativo. La revisión teórica impregnada de temas: (i) el papel de la estrategia en las empresas de base tecnológica, (ii) la iniciativa empresarial tecnológica y la fragilidad de la nueva y (iii) la educación plataformas abiertas como elemento de formación en la estrategia. Los resultados, así como encuestas recogidas en un grupo de enfoque para identificar los principales beneficios se han demostrado en el término medio en relación con la empresa que demuestra los resultados de gestión pertinentes.

Palabras clave: Estrategia; nuevas empresas; Massive Open Course on-line.

\footnotetext{
${ }^{1}$ Mestrando em Empreendedorismo e Inovação pela Faculdade de Economia, Administração e Contabilidade da Universidade de São Paulo - FEA/USP. Brasil. E-mail: artur.tavr@gmail.com

${ }^{2}$ Mestranda pela Faculdade de Economia, Administração e Contabilidade da Universidade de São Paulo - FEA/USP. Brasil. E-mail: renata.malagoli@gmail.com

${ }^{3}$ Doutora em Administração pela Universidade de São Paulo - USP. Professora Pesquisadora da Faculdade Campo Limpo Paulista - FACCAMP. Brasil. E-mail: patricia.krakauer@faccamp.br

${ }^{4}$ Doutor em Medicina Preventiva pela Faculdade de Medicina da Universidade de São Paulo - USP. Professor da Faculdade de Economia Administração e Contabilidade da Universidade de São Paulo - FEA/USP. Brasil. E-mail: mpedroso@usp.br
} 


\section{INTRODUÇÃO}

Um dos temas relatados em literaturas acadêmicas sobre empresas nascentes de base tecnológica é a 'fragilidade do novo' (liability of newness), que resume um conjunto de características comuns ao estágio inicial de novos negócios (Stinchcombe, 1965; Freeman, Carrol \& Hannan, 1983; Deeds \& Rothaermel, 2003). Nesse estágio incipiente, a fragilidade em empresas de tecnologia está associada a uma relativa escassez de recursos. Dentre estes, destacam-se a falta de conhecimento sobre conceitos e ferramentas ligados à estratégia de negócios.

Com recursos escassos, as empresas nascentes e jovens apresentam limitações para contratação de empresas ou consultores especializados com o intuito de apoiar a definição, formalização, execução e acompanhamento das estratégias do negócio (Mizumoto et al., 2010). Tal contexto, geralmente, leva ao descuido das empresas quanto ao seu espectro de gestão, fazendo-se necessária uma busca por meios alternativos para superar a fragilidade do novo e formalizar uma estratégia clara para desenvolvimento do negócio. O presente estudo traz o caso de uma empresa jovem de base tecnológica - denominada no presente artigo como Black Bloom - que, vivenciando tal situação, buscou novos formatos para aquisição de conhecimentos e direcionamento estratégico formal em seus processos.

Frente ao cenário de limitação de recursos em empresas nascentes de base tecnológica (ENBT) e a consequente necessidade de se pensar em alternativas para superar a fragilidade do novo, uma das alternativas para a aquisição de conhecimento necessário para a formalização estratégica de uma empresa com essas características poderia ser a utilização de plataformas abertas de educação para a capacitação profissional.

Alinhando a necessidade da empresa com a pouca disponibilidade de recursos advinda do seu momento organizacional e as tecnologias contemporâneas disponíveis para capacitação, desenhou-se uma intervenção na empresa em estudo nos moldes de uma pesquisa-ação, buscando respostas para a seguinte questão: Dado o contexto de fragilidade do novo, o uso de métodos alternativos para formalização estratégica traz resultados para startups?

A partir do questionamento realizado, que nasce da percepção dos autores e da atualidade da temática no que concerne ao uso de plataformas abertas para a capacitação profissional em empresas, objetivou-se analisar os resultados obtidos com a participação de uma empresa, inserida no contexto da fragilidade do novo, em plataformas abertas de educação (MOOCs), especificamente sobre o processo de formalização estratégica de uma empresa nascente, inserida em um contexto da fragilidade do novo, a partir da percepção de colabores e executivos envolvidos.
Os pontos cobertos no artigo estão centrados em: (i) deficiências apresentadas por uma empresa nascente de tecnologia brasileira; (ii) o mecanismo encontrado para superar a fragilidade do novo; (iii) os processos ligados à formalização e disseminação da estratégia da empresa.

\section{REFERENCIAL TEÓRICO}

Nesta seção buscou-se apresentar alguns trabalhos anteriores que fundamentaram a proposta atual de forma a compor fundamentos para a intervenção realizada e a consequente pesquisa empírica. De modo a responder ao questionamento apresentado na seção introdutória, as principais temáticas discutidas nos próximos itens são: empreendedorismo tecnológico, fragilidade do novo, estratégia e plataformas educacionais alternativas.

\section{O papel da estratégia em empresas de base tecnológica}

Berry (1998) destaca a importância de um olhar diferenciado para o desenvolvimento da estratégia no contexto de empresas de base tecnológica. Para esta autora, o processo de formalização em empresas nascentes de base tecnológica se dá de maneira gradativa, evoluindo de acordo com o estágio de desenvolvimento do negócio. Ao passo que as atividades e o suporte funcional às áreas vão ganhando complexidade, a estratégia da empresa começa a se desdobrar e incluir elementos mais refinados desdobramento no qual os administradores tendem a adotar uma abordagem de pensamento mais estratégico, centrado em longo prazo, não somente reagindo às mudanças que ocorrem com o desenvolvimento do negócio.

Nesse processo, a empresa deixa de se estruturar de maneira reativa e a passar a assumir uma posição proativa, centrada no gerenciamento e otimização dos recursos - momento que geralmente ocorre, segundo a autora, após crises operacionais advindas do crescimento. $\mathrm{O}$ processo de ganho de escala passa a ser, portanto, dependente de visão estratégica, organização operacional e perspectiva de longo prazo para exploração proativa de oportunidades centradas na otimização de recursos. Embora a importância do pensamento estratégico seja reforçada, estudos demonstram que em empresas nascentes de base tecnológica, esse é um recurso ainda deficiente - junto a uma visão estratégica de marketing, capacidade de configurar direções claras e liderança de funcionários a partir destes pontos (Kasabov, 2013).

As competências estratégicas também estão presentes na habilidade de planejar um negócio nascente - o business planning, que, como apresentado por Chwolka e Raith (2012), envolve capacidades como (i) identificar e analisar oportunidades, (ii) 
desenvolver modelos de negócios, (iii) criar estratégias de marketing, (iv) planejar estratégias financeiras, entre outros.

Segundo Rezende (2003), o planejamento estratégico em empresas de base tecnológica pode ser definido da seguinte maneira:

Um processo dinâmico e interativo para determinação de objetivos, políticas e estratégias (atuais e futuras) das funções empresariais e dos procedimentos de uma organização. É elaborado por meio de técnicas administrativas de análise do ambiente (interno e externo), das ameaças e oportunidades, de seus pontos fortes e fracos, possibilita aos gestores estabelecer o rumo para a organização, buscando certo nível de otimização no relacionamento entre empresa, ambiente e mercado. É formalizado para produzir e articular resultados, na forma de integração sinergética de decisões e ações organizacionais. (REZENDE, 2003, p. 147)

Apesar de ser um processo lento e com detalhes, são inúmeras as vantagens de se fazer um planejamento estratégico formal dentro de uma empresa. Embora proposto para o contexto de grandes empresas, Hax e Majluf (1999) propõem vantagens do planejamento estratégico alinhadas à possibilidade de suprir deficiências de empresas nascentes apresentadas por Kasabov (2013):

1) Para a deficiência na clareza de direcionamento: o processo de planejamento estratégico ajuda a unificar as orientações da corporação - com missão, visão e competências funcionais definidas, toda a empresa passa a estar orientada a objetivos comuns.

2) Para as dificuldades no crescimento e orientação em marketing: a segmentação da empresa melhora notoriamente a partir de processo bem definido que reconhece $o$ potencial de cada mercado, bem como reconhece a necessidade de integrações verticais e horizontais de cada setor.

3) Para a deficiência em pensamento estratégico: $\mathrm{o}$ processo de planejamento introduz $\mathrm{o}$ conceito de Longo Prazo - a empresa passa a pensar e se preocupar além das atividades e problemas rotineiros. Ao impor à organização um processo lógico de reflexão com uma sequência de tarefas claramente definidos, o processo de planejamento faz com que o corpo diretivo passe a se orientar de forma criativa aos assuntos de longo prazo.

Dentro desse contexto, o planejamento estratégico é o primeiro dentre todos os níveis de planejamento que devem ser feitos em uma empresa e passa a ser essencial, portanto, para empresas nascentes. Além de definir os objetivos gerais e direcionar todos os membros da companhia em um sentido comum, é um processo que traz aprendizado e promove interação entre as equipes.

Segundo Pinho, Côrtes e Fernandes (2002), as empresas de base tecnológica se caracterizam pelo elevado grau de conhecimento científico incorporado às operações, geralmente se tratando de ciência aplicada e engenharia. Tais autores apresentam alguns pontos ligados aos entraves no desenvolvimento dessas empresas - sendo (i) a baixa capacitação gerencial, (ii) as dificuldades quanto ao processo de escala das operações e (iii) as dúvidas referentes às estratégias tecnológicas a adotar em economias periféricas fatores relevantes para o presente estudo. Quanto à capacitação necessária, a importância do ensino e da formação gerencial é reforçada por Suddaby e Greenwood (2001) ao enfatizarem seu papel em gerar, mensurar e refinar conteúdos gerenciais por meio de pesquisa acadêmica e de práticas de gestão aplicadas ao ambiente empresarial. Segundo os mesmos, "o processo de tentar compreender o conhecimento existente produz novos insights que formam a base de novas tendências gerenciais" (Suddaby \& Greenwood, 2001, p. 936).

Sutton e Rao (2014) reforçam a importância da formalização da estratégia no sentido de fazer com que os fundamentos sejam implementados e que possam vir a ser gerenciáveis nas empresas nascentes de base tecnológica. Para os autores, pilares como alinhamento operacional, definição de prioridades, visão estratégica e engajamento profundo garantem o sucesso do processo de ganho de escala de uma ENBT:

O ganho de escala se desenvolve com menor atrito e maior consistência quando as pessoas que o impulsionam concordam no que está certo e errado - e no que se deve prestar atenção e o que ignorar. O ganho de escala efetivo depende de acreditar e vivenciar uma mentalidade comum entre o grupo, divisão ou organização. (SUTTON \& RAO, 2014, p. 7, tradução nossa)

\section{Empreendedorismo tecnológico e a fragilidade do novo}

Especificamente no campo de negócios em alta tecnologia, Chorev e Anderson (2006) defendem que este perfil de negócio é o direcionador primário para novas economias e seu nível de crescimento, fazendose necessário a concentração em startups de alta tecnologia, que representam oportunidades de grande crescimento e lucratividade. Um exemplo que sustenta o argumento dos autores é o de Israel, considerado uma das referências de mercados em alta tecnologia: de 1990 a 2000, a porção do PIB que o mercado de alta tecnologia representava cresceu mais de 2,5 vezes, o nível de emprego triplicou e o volume de exportação cresceu em grande escala.

A realidade de empresas que estão iniciando suas operações é de grande instabilidade devido a diversos motivos, como inexperiência, poucas 
conexões, capital restrito e falta de posicionamento de mercado. Para isso, surgiu o conceito de liabilities of newness (Stinchcombe, 1965), traduzido para o português como 'a fragilidade do novo'.

Para Freeman et al. (1983), a fragilidade do novo surge devido à dependência da cooperação de estranhos, ausência de legitimidade e discrepância competitiva com organizações já estabelecidas. Os autores citam Stinchcombe (1965) para apontar que, com o tempo, as estruturas passam a se tornar mais estáveis e as ligações com o mercado se solidificam, diminuindo a taxa de mortalidade de tais companhias.

Venkataraman, Van de Vem, Buckeye e Hudson (1990), complementados por Kasabov (2013), exploram, além do aspecto da fragilidade do novo, um conceito que vai um pouco além, mas que também se aplica a empresas nascentes, especialmente empresas com grande dependência de clientes: o conceito de fragilidade do pequeno. Para os autores, a fragilidade do novo, e do pequeno, em ambientes altamente voláteis repercutem em alguns eventos que contribuem para a quebra de empresas, tais como: crises financeiras; incapacidade para administrar rápido crescimento e mudanças; falta de experiência para lidar com turbulências em indústrias específicas; equipe inicial incompleta; planejamento inadequado préstartup e pós-startup para os empreendedores; falta de motivação e compromisso; escolhas erradas em termos de estratégias de nicho; falta de legitimidade; incapacidade de lidar com o aumento da competitividade do mercado; incapacidade de lidar com a volatilidade dos ciclos de mercado. Mizumoto et al. (2010) comentam que empresas jovens também precisam lidar com tais dificuldades, pois, em geral, permanecem nesse estágio como de pequeno porte.

Outra abordagem com sólidas fundamentações é a de Hager, Galaskiewicz e Larson (2004):

De fato, a fragilidade do novo era a culminância de uma variedade de condições, problemas e características organizacionais que tipicamente acompanham as novatas. Stinchcombe (1965) cita quatro destacadas razões pelo motivo de novas organizações serem mais susceptíveis à falência: (1) as dificuldades que novas organizações vivem em reproduzir papéis, estabelecer-se em processos operacionais, criar cultura e aprender habilidades; (2) os altos custos (ou ineficiências) associados com papéis inventados e relações estruturais; (3) problemas inerentes em estabelecer relações de trabalho com estranhos (particularmente empregados); e (4) a incerteza associada com estabelecer ligações com aqueles que utilizam os serviços da organização. (Hager et al. 2004, p. 161, tradução nossa).

Aplicando o conceito de fragilidade à realidade de startups de alta tecnologia, Chorev e Anderson (2006) colocam, em seu artigo Marketing in high-tech start-ups: Overcoming the liability of newness in Israel, as deficiências em relação ao contato com o mercado como grande fragilidade nesse estágio para tal perfil empresarial. Os autores apontam que os riscos relacionados à aceitação do mercado aumentam devido aos produtos serem fundamentados em novas tecnologias geralmente desconhecidas pelos consumidores.

As novas tecnologias também sofrem impacto, em termos de riscos de sucesso, pela falta de experiência por parte dos fornecedores em comercializar, distribuir e oferecer suporte a tal tipo de produto. E, por último, há a questão de o perfil de alta tecnologia geralmente ser liderado por empreendedores com background exclusivamente técnico, fator que gera menor atenção, combinada com falta de confiança, em questões ligadas ao marketing da empresa.

\section{Plataformas abertas de educação como elemento de capacitação em estratégia}

No presente trabalho, o papel da educação está centrado na questão de criação e transmissão de conhecimentos, com ênfase na transferência de fundamentação teórica para o suporte ao empreendedor. Nesse sentido, utiliza-se o conceito de educação empreendedora, apresentado por Andrade e Torkomian (2001) da seguinte maneira:

Pode-se estabelecer que Educação
Empreendedora é o processo que objetiva o
desenvolvimento do ser humano no âmbito da
identificação e aproveitamento de
oportunidades e sua posterior transformação
em realidade, contribuindo assim para a
geração de valores financeiros, sociais e
culturais para a sociedade na qual o ser
humano está inserido. (Andrade \&
Torkomian, 2001, p. 301)

A importância da educação empreendedora, ou ensino de empreendedorismo, é comprovada nos estudos de Kabongo e McCaskey (2011), que apontam uma significante e positiva relação entre a educação empreendedora e a performance dos empreendedores. A evolução nos programas de ensino e nas bases teóricas de empreendedorismo é suportada por Solomon (2007) no seguinte trecho:

O desafio para os educadores será o de desenvolver cursos, programas e campos de estudo que atendam aos rigores da academia enquanto mantém um foco realista e empresarial no ambiente da experiência de aprendizado. O empreendedorismo é um processo contínuo que requer uma miríade de talentos, habilidades e conhecimentos guiados por pedagogias únicas capazes de estimular e transmitir conhecimentos de maneira simultânea (Solomon, 2007, p.168, tradução nossa) 
Abordando a importância de ferramentas e arcabouços teóricos oriundos das escolas de negócios, Suddaby e Greenwood (2001) enfatizam o papel das mesmas para gerar, mensurar e refinar o conteúdo, através da pesquisa acadêmica, de práticas de gestão aplicadas ao ambiente empresarial. Segundo os mesmos, "o processo de tentar compreender o conhecimento existente produz novos insights que formam a base de novas tendências gerenciais" (Suddaby \& Greenwood, 2001, p. 936).

A transferência do conhecimento se mostra relevante sob a ótica da organização de recursos para exploração de oportunidades, especialmente no que tange aos recursos humanos qualificados em gerenciamento e visão estratégica. No estudo "Explaining Growth Paths of Young Technology-Based Firms: Structuring Resource Portfolios in Different Competitive Environments" (Clarysse, Bruneel e Wright, 2011), defende-se que um dos desafios de empresas nascentes de tecnologia é a existência de capital humano experiente e capacitado em gestão nos primeiros anos dessas empresas, bem como a organização de um portfólio claro. As competências estratégicas destacadas nesse estudo, segundo Chwolka e Raith (2012), podem ser ensinadas - abrindo assim oportunidades para educadores desenvolverem programas de capacitação centrados nos aspectos apresentados pelos autores no primeiro tópico deste referencial teórico.

Com o aumento da presença de tecnologias, tais como o acesso a internet de qualidade, novas possibilidades surgiram para a transferência de conhecimento - uma delas são os Massive Online Open Courses (MOOCs), considerada por Rodriguez (2012) um importante passo dentro da educação online, uma vez que pode atender muitas pessoas de diferentes localidades. A filosofia de tais cursos é baseada na conectividade e mudanças conceituais que entendem o professor como facilitador do aprendizado. Tais avanços nos horizontes de capacitação começam a ter suas implicações em ambientes corporativos, como apresentado por Dodson e Kitburi (2015), que reforçam o papel dos MOOCs no suprimento de gaps de competências e aumento de produtividade em seus recursos humanos.

Para Yuan e Powell (2013), o crescente número de instituições envolvidas com tal modalidade de ensino surge visando a expansão em termos de público, melhorias em marketing e branding, bem como o potencial de conseguir novos meios de geração de receita. O termo, utilizado pela primeira vez, em 2008, representa uma metodologia emergente de ensino que tem como característica principal a conectividade social, a facilidade de se ter um expert como facilitador e o acesso livre ao conhecimento (Rodriguez, 2012). O crescimento dos MOOCs tem também resultado em questionamentos em termos de retenção de alunos e eficácia na transferência completa do conteúdo ao longo do curso, reflexão gerada no estudo de Breslow et. al. (2013), que também direcionam o aprofundamento em questões como as metas dos alunos ao se engajar em um MOOC - e suas relações com as interações no curso -, os fatores motivadores e desmotivadores ao longo de um curso e outros pontos mais profundos em termos de aprendizagem.

Radford, Coningham e Horn (2015) destacam no estudo "MOOCs: Not Just for College Students How Organizations Can Use MOOCs for Professional Development" o fato de que, embora seja um fenômeno recente cuja riqueza dos dados ainda não permite uma avaliação criteriosa sobre impactos em perfomance, existe a percepção de impacto positivo no desenvolvimento de capital humano. Um dos dados levantados pelo estudo é o fato de $76 \%$ dos funcionários analisados afirmarem que enxergariam ou enxergariam a sua empresa - se utilizando dos MOOCs para desenvolvimento profissional.

Vislumbrou-se no presente estudo a possibilidade de utilização de MOOCs como alternativa para a capacitação de profissionais de startups - que por natureza estão inseridas em um contexto da fragilidade do novo e do pequeno, com características particulares de tal realidade (Venkataraman et. al.,1990). Tal escolha foi reforçada pelo fato de se possuir como participantes gestores, mentores e profissionais, fato que se alinha ao mencionado no estudo de Rodriguez (2012) e Hew e Cheung (2014), que acrescentam que uma das motivações dos participantes de MOOCs é obter ajuda para com o seu trabalho. Apesar dos estudos investigados na presente revisão teórica não mencionarem que a finalidade de tais cursos fosse a capacitação profissional, dado o perfil dos participantes, essa seria uma possibilidade a ser investigada com a atual pesquisa-ação delineada.

\section{PROCEDIMENTOS METODOLÓGICOS}

Dado o caráter intervencionista da proposta, o método do estudo se embasou no conceito de pesquisaação, considerada por Soares et. al. (2009, p. 117) como "um tipo de investigação participante que tem como característica peculiar o propósito de ação planejada sobre os problemas detectados" e definida por Thiollent (2008, p. 14) como "um tipo de pesquisa social com base empírica que é concebida e realizada em estreita associação com uma ação ou com a resolução de um problema coletivo e no qual os pesquisadores e os participantes representativos da situação ou problema estão envolvidos de modo cooperativo ou participativo". Tal condição atende a proposta da atual pesquisa, uma vez que um dos pesquisadores estava envolvido na gestão da empresa e foi um dos responsáveis pela elaboração da ação de intervenção.

A empresa selecionada para a realização da intervenção é uma empresa jovem, que, segundo Mizumoto et al. (2010) faz com que tenha dificuldades características das listadas como da fragilidade do novo 
e do pequeno, caracterizando-a como elegível para o estudo da temática desta proposta. Resguardada as especificidades da empresa, seguiram-se os procedimentos explicitados por Thiollent (2008), a saber: (i) diagnóstico inicial, (ii) definição do problema prático a ser investigado, (iii) levantamento do marco teórico, (iv) execução da intervenção, (v) realização de seminários e (vi) coleta dos dados. Explicita-se que para a análise dos resultados obtidos, será utilizada a proposta de Mello et. al. (2012), apresentada na próxima seção.

O problema prático a ser investigado dizia respeito a como solucionar questões inerentes a fragilidade do novo, principalmente as relacionadas a recursos financeiros, de forma a obter conhecimentos necessários para suprir demandas relacionadas ao processo estratégico, especificamente relacionada a comercialização em escala dos serviços prestados pela Black Bloom, dada a necessidade de momento da startup.

Duas interações principais ocorreram no segundo semestre de 2014 e no primeiro semestre de 2015: a primeira foi a participação em um curso online da Stanford University, por meio da plataforma NovoEd, e a segunda, a aplicação de um workshop envolvendo alguns dos profissionais atuantes na área estratégica da empresa, seguindo um dos passos preconizados por Thiollent (2008), no que tange a etapa 'seminários'.

Como procedimento de coleta de dados e atendendo ao objetivo delineado para o presente estudo, foi utilizado o grupo focal para levantar percepções e opiniões acerca dos resultados obtidos com as interações realizadas. A opção por esse procedimento considerou o preconizado por Gatii (2005) que considera ser um procedimento adequado para a pesquisa-ação, sendo definido por Giovinazzo (2001) como um método de pesquisa qualitativa onde o foco ou objetivo da análise é a interação existente no grupo onde ocorre, sendo que os participantes influenciam uns aos outros no momento da discussão e apresentação de ideias.

Para Oliveira e Freitas (1998), quando aplicado corretamente, o grupo focal traz resultados efetivos, evidenciando como as pessoas pensam, sentem e até mesmo permite depreender a forma como o público participante reage em relação aos temas discutidos. Utilizou-se um roteiro, proposto por Santos e Fogliatto (2002) para aplicação da técnica do grupo focal, contento seis etapas sequenciais: (i) planejamento do grupo focalizado, (ii) identificação dos participantes, (iii) elaboração de questões e roteiro, (iv) definição de funcionamento e aspectos logísticos, (v) escolha do moderador e condução de entrevistas, e (vi) análise dos dados.

(i) Planejamento do grupo focalizado: esta etapa foi realizada ainda quando os participantes estavam atendendo ao curso online de Stanford, no momento em que se iniciaram as atividades de grupo e toda a teoria já havia sido discutida. Determinou-se que o objetivo central da realização do grupo focal seria entender e discutir com alguns sócios-executivos da empresa quais eram suas percepções acerca de temas diretamente ligados a estratégia e escalabilidade da empresa.

(ii) Identificação dos participantes: foram escolhidos para participar das discussões quatro sócios-executivos da empresa, diretamente ligados a operação e rotinas, bem como mais quatro líderes de diferentes áreas como tecnologia e produto.

(iii) Questões e roteiro: as questões foram escolhidas de forma a abordar de forma direcionada, temas como estrutura organizacional, gestão do conhecimento e recursos humanos. Estes temas surgiram da própria abordagem do curso online realizado, que sugere esses como pontos diretamente relacionados a escalabilidade e bom desdobramento estratégico.

(iv) Funcionamento e aspectos logísticos: Uma vez que os oito participantes estavam localizados em cidades diferentes, escolheu-se como local de realização a sede da empresa, onde estava a maioria dos participantes. Selecionou-se uma data para realização do workshop e então iniciaram-se preparativos para as atividades, como compra de passagens, organização do local e material necessário para as discussões.

(v) Escolha do moderador: o moderador escolhido foi aquele que tanto tinha feito o curso online quanto fazia parte do quadro de sócio executivo da empresa, para que tivesse os dois contextos e pudesse garantir melhor aproveitamento das discussões.

(vi) Realização do grupo focal: o grupo focal aconteceu em Manaus, cidade sede da empresa e teve duração aproximada de 2 horas e meia. Os dados obtidos com a coleta realizada no grupo focal foram analisados através dos conteúdos transcritos, sendo que, na prática, se transformaram em ações imediatas, conforme será explicado no próximo item.

(vii)Implementação e Ações: Durante as discussões, todas as percepções dos oito participantes para cada uma das questões eram registradas em um formato onde o moderador agrupava visões convergentes e divergentes. Em grande parte das discussões, identificou-se necessidade de mudança em métodos e rotina da 
empresa. Identificadas as oportunidades, quando se atingia um consenso entre os participantes, gerava-se uma ação imediata para ser implementada na empresa.

Informações adicionais sobre a empresa, de forma que a mesma pudesse ser apresentada nesta pesquisa, foram obtidas através da coleta de dados secundários, realizada através de documentos da empresa e do site da mesma.

\section{A PESQUISA-AÇÃ̃o}

Nesta seção, serão apresentados os elementos percebidos com a pesquisa-ação, seguindo a lógica proposta por Mello et. al. (2012) para a apresentação das interações realizadas e os resultados alcançados: (i) análise dos dados, no qual há uma apresentação do contexto da empresa, suas relações com a teoria apresentada e a motivação gerada para a pesquisa-ação; (ii) implementação, momento em que é descrita a intervenção proposta e seu embasamento; (iii) descrição de resultados, com os dados coletados após a intervenção acerca de percepções e aprendizados.

\section{Análise de dados: o contexto da empresa e propósito da pesquisa-ação}

A Black Bloom (nome fictício) é uma startup de tecnologia, que trabalha com capital próprio nacional, vindo de aporte de um grupo de investidores. A empresa se divide em três grandes grupos de gestão: investidores, tecnologia e negócio. A empresa atua como B2B (business to business), como fornecedora de serviços de software que melhoram a experiência de vendas de empresas que atuam no varejo, seja físico, seja eletrônico.

No momento da realização desta pesquisa a empresa possuía 50 funcionários e 20 clientes, sendo que a receita é proveniente da venda de 4 soluções principais, e alguns derivados destes. Naquele momento apresentava um crescimento no faturamento de cerca de $45 \%$ e passava por um processo de reestruturação e redesenho de processos, buscando uma base para escalar sua operação, porém, sob receio de assumir riscos e problemas relacionados à ação de escala.

Com três anos de operação e consolidando sua presença no mercado, a empresa nasceu da venda de um primeiro único produto, fruto da intenção de um grupo de pesquisadores em participar de um concurso de mercado em tecnologia. Após verificarem a existência de mercado para o produto desenvolvido em projeto pontual para este concurso, o grupo começou a buscar um primeiro cliente para testar as regras e funcionalidades do ativo desenvolvido.

Neste momento, enxergando potencial no produto desenvolvido até aquela data, um grupo de investidores resolveu aportar capital e executivos para operacionalizar o negócio, se envolvendo inicialmente com frentes comerciais e jurídicas daquela que começava a trilhar caminhos de uma nova startup. De um grupo de sete pesquisadores e um protótipo, a Black Bloom se constituiu como empresa, com um grupo de investidores-executivos e desenvolvedores e após um ano conseguiu seu primeiro cliente. Este cliente veio a ser um fator importante no desenvolvimento dessa startup, pois foi através de feedbacks e novas demandas vindas desse cliente, a empresa começou a crescer e iniciar seu processo de escalar.

Em seu segundo ano de operação, a empresa sentiu necessidade de formalizar áreas de: (a) Atendimento ao cliente: técnico; (b) Atendimento ao cliente: comercial; (c) Desenvolvimento: ajustes e novas funcionalidades do produto e (d) Jurídico e financeiro: elaboração de contratos e controle de caixa.

Com essa estrutura a empresa cresceu o suficiente para atender o cliente e melhorar seu produto. Atingia-se, considerando sócios e demais pessoas contratadas ao longo do ano, um quadro de cerca de 18 (dezoito) funcionários. Ao longo de um ano de operação com esse cliente, foram feitos testes de validação do produto e intenso processo de melhoria continuada, até atingir o estágio de produto maduro e robusto, cujos sócios consideravam estar pronto para ser vendido a outros clientes.

Ao se projetar ao mercado, a startup deparou-se com o desafio de entendimento mais profundo de cada negócio de seus clientes. Foi percebido um conhecimento profundo acerca do cliente atual, mas havia a consciência de que, para ganhar novos clientes, era necessário conhecer mais do seu meio de atuação, os problemas, os desafios e até mesmo imergir na realidade do mercado para entender onde mais poderiam lhes ajudar. Este momento da empresa se faz interessante ao estudo por trazer dados empíricos alinhados às premissas apresentadas na teoria destacando questões como a fragilidade do novo e as dificuldades de crescimento e ganho de escala.

Foi então que os sócios da startup decidiram agregar ao quadro de sócios-executivos um grupo de negócio - focado em agregar uma visão nesta área, cujo entendimento ainda era superficial. Com esse movimento, melhorou-se o processo de expansão e busca de novos clientes - outro elemento correlato à teoria de Berry (1998) da necessidade de evolução estratégica para exploração proativa de oportunidades.

Em seu terceiro ano de operação a empresa conseguiu se expandir em duas direções: (i) Expansão da carteira de clientes: Crescimento de um para cerca de oito clientes. Foram integradas à carteira clientes de diferentes setores, o que pode conferir à startup uma diversidade de desafios e também de aprendizado sobre os diferentes nichos existentes. (ii) Ampliação de portfólio: Lançamento de um segundo produto. Por meio da frequente interação com seus clientes, a empresa percebeu a oportunidade de desenvolver um 
segundo produto que fosse ligado ao produto inicial e que atenderia uma lacuna existente em grande parte de seus clientes.

Dessa maneira, no momento do presente estudo a empresa estava em seu quarto ano de operação e já atingia cerca de 20 clientes, contando com uma estrutura de quase cinquenta funcionários (Figura 1) e com um quadro organizacional mais robusto.

Figura 1 - Estrutura organizacional da Black Bloom

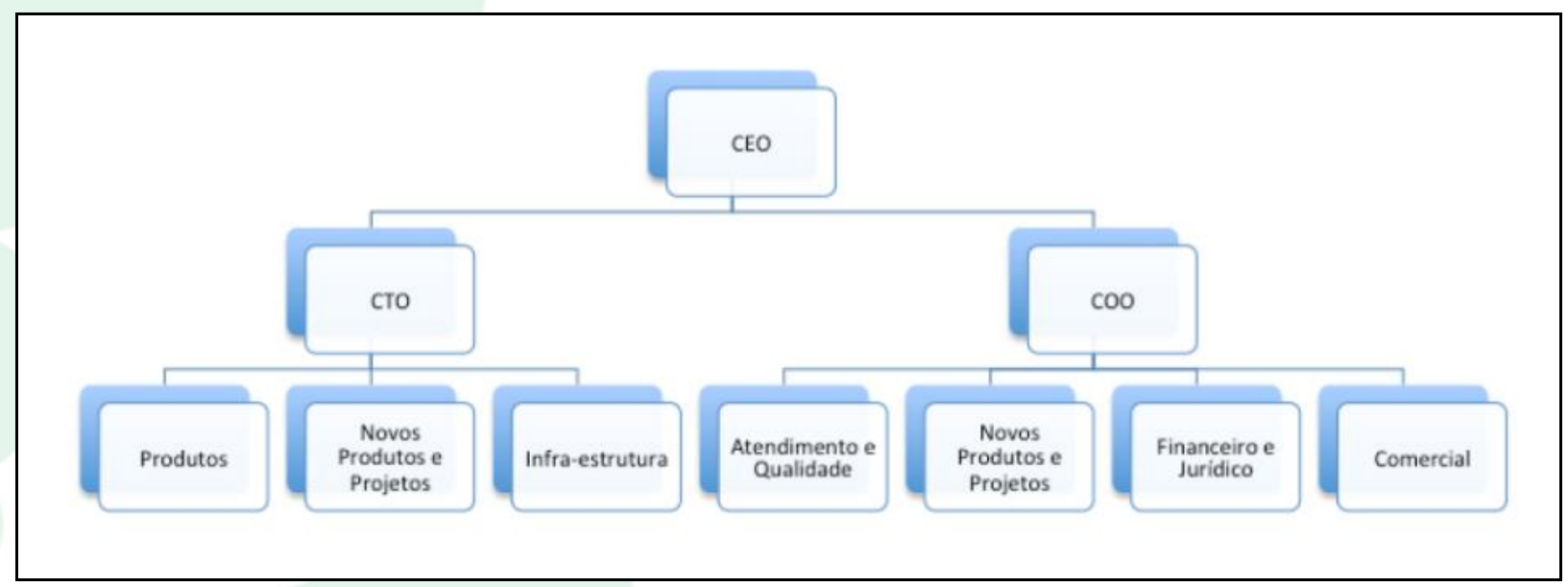

Fonte: Autores

Com mais clientes, mais produtos e uma estrutura hierárquica mais burocrática, a startup passou a enfrentar desafios de consequência direta ao seu crescimento. Questões de escalabilidade, questionamento estratégico, gestão do conhecimento e estrutura organizacional passaram a ser mais frequentes nas discussões do corpo diretivo da empresa. Neste momento da empresa uma pesquisa-ação desdobrou sua intervenção com o propósito de formalização da estratégia e fortalecimento das operações frente aos efeitos colaterais das 'dores do crescimento'.

\section{Implantação: a experiência de formalização da estratégia}

No contexto da fragilidade do novo e limitação de recursos, a proposta alternativa para aquisição de conhecimentos relativos ao processo de formalização da estratégia e escalabilidade foi a busca por conhecimentos em uma plataforma MOOC (Massive Online Open Course) da Universidade de Stanford, vivenciando o curso Scaling Up Your Venture Without Screwing Up. A utilização do MOOC se mostrou financeiramente mais interessante se comparada à contratação de consultoria externa ou treinamentos in company. No workshop, realizado após a participação no curso, discutiu-se sobre transferência dos conhecimentos e formalização da estratégia da empresa.

O curso à distância teve a duração total de cinco semanas e foi direcionado a fundadores e gestores de startups que tivessem o interesse em se aprofundar nas etapas e experiências de se escalar uma empresa. Conduzidos pelos professores da Stanford University, Robert Sutton e Huggy Rao, os módulos foram baseados no livro Scalling up Excellence (Sutton \& Rao, 2014) e explorados em vídeo aulas teóricas e entrevistas com profissionais de mercado. Os seguintes temas foram trabalhados no curso:

1. O fracasso - como lidar com histórias e casos de fracasso;

2. Mindset da empresa - como está embasada e disseminada a cultura dentro da empresa e seus integrantes;

3. Padronização vs Customização - a decisão se a empresa servirá seus produtos sempre da mesma maneira ou se haverá alguma flexibilidade e customização de acordo com os clientes;

4. Fazendo a roda girar - a presença de uma causa maior que norteiam os integrantes da empresa e a possibilidade de inovar e produzir coisas diferentes e legais;

5. Complexidade - como estruturar a empresa para diminuir burocracia, sobrecarga e aumentar a autonomia entre os times;

6. Contratação de funcionários - como contratar e manter talentos. Como fazer com que os funcionários se sintam donos do negócio;

7. Conexões em cascata - como disseminar conhecimento, experiências e excelências entre todos as áreas da empresa;

8. O mal - como cortar o mal da empresa pela raiz? Como promover o bom e evitar que coisas ruins contaminem a empresa.

Para cada módulo apresentado, foram feitos exercícios em grupo e estes eram discutidos e comentados por todos os alunos participantes de 
maneira colaborativa - formato peer review. Utilizando um material que resumia e exemplificava cada um dos tópicos tratados ao longo do curso, promoveu-se o workshop, nos moldes de um seminário, como proposto por Thiollent (2008) com a participação dos sócios da empresa Black Bloom, que estavam diretamente ligados à operação da empresa e quatro líderes de diferentes assuntos da empresa. O conteúdo do material estava concentrado em três etapas principais:

(i) Teoria: apresentar o conceito de cada umas das "etapas" para discutir a escalabilidade da empresa.

(ii) Reflexão: exemplos práticos de algumas empresas e aplicação do conceito apresentado na Black Bloom.

(iii) Exercício: Criar um plano de ação ou lista de tarefas que pudessem ajudar na implementação prática da teoria apresentada.

\section{Resultados obtidos com a intervenção}

O grupo de discussões promovido pela empresa após a participação dos sócios e líderes no curso descrito acima apresentaram certa complexidade, porém, os resultados demonstraram um caráter bastante produtivo na reflexão. Segundo Sutton e Rao (2014) todo líder em uma organização tem o desafio de espalhar crenças e comportamentos construtivos de inicialmente poucos, para posteriormente muitos funcionários na empresa.

As discussões foram promovidas em torno dos três questionamentos: Complexidade, Contratação de funcionários e Conexões em cascata. Cada um deles será abordado a seguir.
1. Complexidade: $\mathrm{O}$ processo de crescimento e amadurecimento é inerente às empresas de boa performance, havendo uma consequência possível - a da construção de uma estrutura burocrática e complexa onde as pessoas perdem a capacidade e poder de focar em coisas corretas e importantes (Rao \& Sutton, 2014). Como resultado das discussões, reflexões e exercícios feitos sobre esse tema, constatou-se que a empresa estava engessada e muito burocratizada com a estrutura verticalizada e segregada que estava vigente. Percebese a necessidade de implementar um formato onde gerasse autonomia e mais integração entre os times. Nesse contexto, a empresa chegou ao final das discussões com uma nova proposta de estrutura hierárquica (Figura 2). Essa nossa estrutura foi pensada para reunir as pessoas de acordo com temas ou atividades que desempenham, em grupos com autonomia e liderados por uma pessoa, que por consenso toma decisões com demais líderes de outros grupos - deixando assim a operação mais simples e autônoma.

Figura 2 - Nova estrutura hierárquica Black Bloom

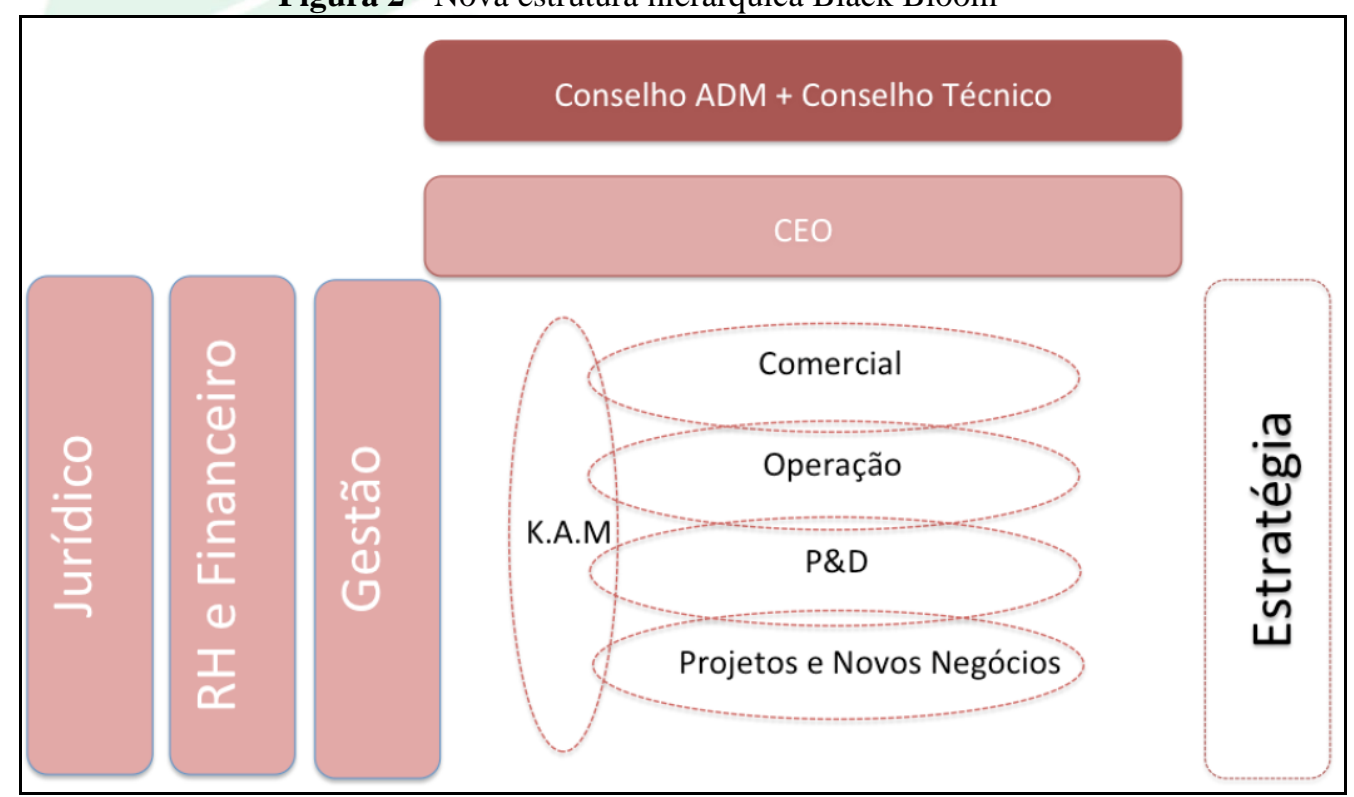

Fonte: autores 
2. Contratação de funcionários - Segundo Sutton e Rao (2014), contratar pessoas com valores, personalidade e habilidades alinhadas à necessidade da empresa é fundamental no processo de escalar uma empresa nascente de base tecnológica. Sendo assim, a empresa refletiu e elaborou um processo de busca contínua por funcionários, fortalecendo sua parceria com Universidades e melhorando sua comunicação de vagas e perfil da empresa.

3. Conexões em cascata - Como proposta para disseminar conhecimento, experiências e excelências entre todos as áreas da empresa, propôs-se a criação de duas rotinas dentro da empresa: (i) Black Bloom School - com a frequência inicial de uma vez a cada quinze dias, um funcionário da empresa dará uma "aula" aberta a todos os demais funcionários sobre sua expertise; (ii) Job Rotation - a empresa deverá estrutura um processo onde os funcionários trocam de funções e times com uma certa frequência.

Durante as discussões desses três tópicos principais, demais temas que surgiram como cultura, liderança, as influências negativas e proposta de atuação da empresa no mercado foram discutidos e fortaleceram o posicionamento prévio de Missão, Visão e Valores da empresa.

Complementando os dados ligados aos resultados de curto prazo, cabe reforçar os resultados mapeados a médio prazo - com dados relativos à empresa após um pouco mais de um ano da intervenção. A empresa Black Bloom atingiu cerca de trinta clientes na carteira, mais de 60 (sessenta) funcionários e, em seu quinto ano de operação, foi vendida para uma empresa de capital aberto em bolsa que adquiriu a Black Bloom e uma outra empresa concorrente por mais de 78 (setenta e oito) milhões de reais. Pontos chave para o sucesso da negociação, segundo um dos sócios da empresa adquirida, destacando em uma entrevista pública, foram o capital intelectual da empresa e as estratégias bem definidas da operação.

\section{DISCUSSÃO DOS RESULTADOS}

Com o aumento da presença de tecnologias, como o acesso à internet de qualidade, novas possibilidades surgiram para a transferência de conhecimento, e uma delas são os Massive Online Open Courses (MOOCs). Para Yuan e Powell (2013), o crescente número de instituições envolvidas com tal modalidade surge com o objetivo de expandir o acesso em termos de público, melhorias em marketing e branding, bem como o potencial de conseguir novos meios de geração de receita.

Neste trabalho, percebeu-se uma grande oportunidade de utilizar uma nova forma de transferência de conhecimento para gerar discussões e atuar sobre possíveis falhas que estavam sendo observadas no ciclo de desenvolvimento de uma startup de tecnologia. Em uma empresa nascente de base tecnológica (ENBT), onde os recursos na maioria das vezes são escassos, é vital que novas fontes de conhecimento sejam procuradas e utilizadas como forma de desenvolvimento.

A realidade da empresa Black Bloom exposta nesse trabalho, se alinha ao conceito da "fragilidade do novo" proposto por Stinchcombe (1965): há instabilidade no dia a dia da empresa, diretamente relacionada à inexperiência dos executores, poucas conexões ou conexões não devidamente estruturadas e capital restrito. Neste caso, o tempo atrelado à uma atividade realizada na empresa liderada por um dos sócios-executivos após a execução de um curso online foram fatores chave para trazer mais maturidade e estabilidade ao processo da empresa, especialmente no que diz respeito a estrutura organizacional e gestão do conhecimento.

Sem a necessidade de contratação de empresas de consultoria e dispêndio de recursos que a empresa não dispunha, após a intervenção realizada e o trabalho organizado por pessoas do próprio time, embasados pela teoria do curso online, a startup ganhou:

1) uma nova estrutura organizacional, mais colaborativa, funcional e menos hierárquica, funcionando com líderes eleitos e mais integrados entre si;

2) uma nova metodologia e processo de contratação de recursos; e

3) dois novos processos voltados a promover capacitação e compartilhamento de conhecimento.

Com os resultados alcançados, percebeu-se que um dos aspectos listados na literatura no que concerne a fragilidade do novo e do pequeno (Venkataraman et. al.,1990), relacionado a falta de recursos e pouco conhecimento estratégico, pode ser transpassada com criatividade e uso da tecnologia que possibilitou o acesso a abordagens online de educação como os MOOCs.

Outro tema que teve sua relevância constatada com os resultados foi o compartilhamento e disseminação do conhecimento como geração de novas tendências, como foi dito por Suddaby e Greenwood (2201) "o processo de tentar compreender o conhecimento existente produz novos insights que formam a base de novas tendências gerenciais" 
(Suddaby \& Greenwood, 2001, p. 936). Atendem também a outro aspecto mencionado por Stinchcombe (1965) no que diz respeito às dificuldades operacionais existentes em empresas inseridas nessa realidade. Com a aquisição do conhecimento e, principalmente, com a transferência do mesmo, pode-se perceber um ganho relacionado ao processo operacional da startup.

No que tange ao papel dos MOOCs, foi percebido o alinhamento com a teoria na proposição da aplicação de tais ferramentas em processos de desenvolvimento profissional e amadurecimento de competências ao capital humano da organização (Dodson \& Kitburi, 2015). Além disso, ao se comparar com o estudo de Radford et al. (2015) e suas sugestões de estudos futuros, há um avanço na teoria no que tange ao impacto gerado pelo papel dos MOOCs em um contexto corporativo, trazendo neste estudo uma primeira situação na qual há impacto percebido em termos de capacitação organizacional e resultados documentados.

\section{CONSIDERAÇÕES FINAIS}

Com o presente estudo percebeu-se que os conceitos apresentados em relação à fragilidade do novo se aplicavam à realidade da Black Bloom, especialmente em relação ao ganho de escala da operação, disseminação do conhecimento e estrutura organizacional da empresa. Conforme apresentado na teoria, foi possível utilizar novas plataformas de ensino, como os MOOCs, para oferecer melhor capacitação e embasamento para as decisões referentes aos problemas enfrentados, o que responde ao questionamento da pesquisa. $\mathrm{O}$ uso de tal plataforma foi, portanto, bastante útil na elaboração de um plano de melhoria para as deficiências da empresa. Apesar dos resultados obtidos com a intervenção, relatados nos capítulos anteriores, a investigação carece de um estudo ao longo dos próximos anos, de forma a coletar dados que possam subsidiar uma análise do impacto de tais resultados no planejamento estratégico da empresa - sendo esta uma sugestão para estudos complementares.

A partir dos resultados obtidos, entende-se como contribuição do estudo proposto à prática empresarial o reforço dado a dois elementos: (i) a necessidade de maior orientação estratégica a empresas nascentes de base tecnológica e (ii) a possibilidade do uso de MOOCs como elemento de apropriação de conhecimento em contextos de recursos escassos. Como suporte à orientação estratégica, o presente estudo trouxe elementos operacionais relevantes, propostas para otimizar a gestão do conhecimento e abordagens em pontos estratégicos - como estrutura organizacional. No aspecto das possibilidades do uso de MOOCs, o estudo apresentou, com os resultados alcançados e seu alinhamento com autores que propõem essa aplicação em ambientes corporativos, elementos que trazem primeiras comprovações de oportunidades no uso desses recursos.

Destacam-se algumas limitações metodológicas inerentes a própria escolha do método: (i) a proximidade existente entre um dos pesquisadores e os sócios da startup que, por um lado, facilitou o acesso e a intervenção propriamente dita, mas, por outro, pode ter causado viés; (ii) a coleta de dados restringiu-se a realização de um grupo de discussão e aos sócios da empresa e (iii) os resultados obtidos restringem-se ao contexto investigado, não cabendo, dada a escolha do método, generalizar para outras startups. Sugerem-se estudos futuros: estudos com múltiplos casos e, na sequência, levantamentos quantitativos com participantes de cursos com esta natureza.

\section{REFERÊNCIAS}

Andrade, R. F. \& Torkomian, A. L. V. (2001). Fatores de influência na estruturação de programas de educação empreendedora em instituições de ensino superior. Artigo apresentado no II EGEPE, Londrina, Brasil.

Breslow, L., Pritchard, D. E., DeBoer, J., Stump, G. S., \& Seaton, D. T. (2013). Studying learning in the worldwide classroom: Research into edX's first MOOC. Research \& Practice in Assessment, 8:1325 .

Chorev, S. \& Anderson, A. R. (2006). Marketing in high-tech start-ups: Overcoming the liability of newness in Israel. International Entrepreneurship and Management Journal, 2(2):281-297.

Chwolka, A. \& Raith, M. G. (2012). The value of business planning before start-up - A decisiontheoretical perspective. Journal of Business Venturing, 27: 385-399.

Clarysse, B., Bruneel, J. \& Wright, M. (2011). Explaining Growth Paths of Young TechnologyBased Firms: Structuring Resource Portfolios in Different Competitive Environments. Strategic Entrepreneurship Journal, 5: 137-157.

Deeds, D. L. \& Rothaermel, F. T. (2003). Honeymoons and liabilities: The relationship between age and performance in research and development alliances. The Journal of Product Innovation Management, 20:468-484.

Dodson, M. N. \& Kitburi, K. (2015). Possibilities for MOOCs in corporate training and development. Performance Improvement, 54(10): 14-21. 
Freeman, J., Carroll, G. R. \& Hannan, M. T. (1983). The liability of newness: Age dependence in organizational death rates. American Sociological Review, 48(5):692-710.

Gatti, B. A. (2005). Grupo focal na pesquisa em ciências sociais e humanas. Brasília: Líber.

Giovinazzo, R. A. (2001). Focus group em pesquisa qualitativa - fundamentos e reflexões. Administração On Line, 2(4), out-nov-dez. Disponível em <http://www.fecap.br/adm_online/>. Acesso em $27 / 06 / 2016$

Hager, M. A., Galaskiewicz, J. \& Larson, J. A. (2004). Structural embeddedness and the liability of newness among nonprofit organizations. Public Management Review, 6(2):159-188.

Hax, A. C. \& Majluf, N. S. (1999). Estrategias para el liderazgo competitivo. Barcelona: Granica.

Hew, K. F. \& Cheung, W. S. (2014). Students' and instructors' use of massive open online courses (MOOCs): Motivations and challenges. Educational Research Review, 12:45-58.

Kabongo, J. D. \& Mccaskey, P. H. (2011). An examination of entrepreneurship educators' profiles in business programs in the United States. Journal of Small Business and Entreprise Development, 18(1):27-42.

Kasabov, E. (2013). Start-Up Difficulties in EarlyStage Peripheral Clusters: The Case of IT in an Emerging Economy. Entrepreneurship Theory and Pratice, 39(4): 727-761.

Mello, C. H. P., Turrioni, J. B., Xavier, A. F. \& Campos, D. F. (2012). Pesquisa-ação na engenharia de produção: proposta de estruturação para sua condução. Revista Produção, 22:1-13.

Mizumoto, F. M., Artes, R., Lazzarini, S. G., Hashimoto, M. \& Bedê, M. A. (2010). A sobrevivência de empresas nascentes no estado de São Paulo: um estudo sobre capital humano, capital social e práticas gerenciais. Revista de Administração da USP, 45 (4): 343-355.

Oliveira, M. \& Freitas, H. (1998). Focus group, pesquisa qualitativa: resgatando a teoria, instrumentalizando o seu planejamento. Revista de Administração, 33(3):83-91.

Pinho, M., Côrtes, M. R. \& Fernandes, A. C. (2002). A fragilidade das empresas de base tecnológica em economias periféricas: uma interpretação baseada na experiência brasileira. Ensaios Fee, Porto Alegre, 23(1):135-162.

Radford, A. W., Coningham, B. e Horn, L. (2015). MOOCs: Not Just for College Students - How Organizations Can Use MOOCs for Professional Development. Employment Relations Today, 41(4): $1-15$.

Rodriguez, C. O. (2012). MOOCs and the AI-Stanford like Courses: Two Successful and Distinct Course Formats for Massive Open Online Courses. European Journal of Open, Distance and ELearning. Disponível em:

http://www.eurodl.org/index.php?p=archives\&year=20 13 \&halfyear $=2$ \&article $=516$ Acesso em: $15 / 06 / 2016$.

Rezende, D. A. (2003). Metodologia para projeto de planejamento estratégico de informações alinhado ao planejamento estratégico: a experiência do Senac-PR. Ciência da Informação, 32(3):146-155.

Santos, G. T. \& Fogliatto, F. S. (2002). Grupos focalizados: uma proposta de roteiro para identificação de atributos de preferência. Artigo apresentado no XXII ENEGEP, Curitiba, Brasil.

Solomon, G. (2007). An examination of entrepreneurship education in the United States. Journal of Small Business and Enterprise Development, 14(2):168-182.

Stinchcombe, A. L. (1965). Social structure and organizations. In: March, J. G. Handbook of Organizations, 153-193.

Soares, M., Paton, C., dos Santos, A. F., \& Bezerra, F. A. (2009). Uma discussão sobre a viabilidade da pesquisa-ação na contabilidade. Revista de Contabilidade e Organizações, 3(7):109-126.

Suddaby, R. \& Greenwood, R. (2001). Colonizing knowledge: commodification as a dynamic of jurisdictional expansion in professional service firms. Human Relations, 54 (7):933-953.

Sutton, R. I. \& Rao, H. (2014). Scaling up excellence: getting to more without settling for less. New York: Crown Business.

Thiollent, M. (2008). Metodologia da pesquisa-ação. 18a. ed. São Paulo: Cortez.

Venkataraman, S., Van de Ven, A., Buckeye, J. \& Hudson, R. (1990). Starting up in a turbulent environment: a process model of failure among firms with high customer dependence. Journal of Business Venturing, 5(5):277-295. 
Formalização da Estratégia em Empresas Nascentes de Base Tecnológica: Recursos Alternativos na Fragilidade do Novo

Yuan, L. \& Powell, S. (2013). MOOCs and open education: implications for higher education. JISC CETIS White Paper. Disponível em: http://publications.cetis.org.uk/2013/667 Acesso em: 15/06/2016. 